NASA Technical Memorandum 100030

\title{
Interfacial Adhesion: Theory and Experiment
}

\author{
(LASA-TH-100830) INTEEFACIAL ALEESION: \\ TEECBY ARD EXEEBIEENT (NASA) 22 P CSCL 11F
}

N88-20417

Unclas

G 3/26 0133303

John Ferrante

Lewis Research Center

Cleveland, Ohio

Guillermo H. Bozzolo

Case Western Reserve University

Cleveland, Ohio

Clarence W. Finley

Pennsylvania State University

New Kensington, Pennsylvania

and

Amitava Banerjea

Lewis Research Center

Cleveland, Ohio

Prepared for the

Spring Meeting of The Materials Research Society

Reno, Nevada, April 5-9, 1988 
INTERFACIAL ADHESION: THEORY AND EXPERIMENT

\author{
by \\ John Ferrante \\ National Aeronautics and Space Administration \\ Lewis Research Center \\ Cleveland, Ohio 44135 \\ Guillermo H. Bozzolo \\ Department of Physics \\ Case Western Reserve University \\ Cleveland, Ohio 44106 \\ Clarence W. Finley \\ Chemistry Department \\ Pennsylvania State University \\ New Kensington Campus \\ New Kensington, Pennsylvania 15068 \\ and \\ Amitava Banerjea \\ National Aeronautics and Space Administration \\ Lewis Research Center \\ Cleveland, Ohio 44135
}

\title{
ABSTRACT
}

Adhesion, the binding of different materials at an interface, is of general interest to many branches of technology, e.g., micro-electronics, tribology, manufacturing, construction, etc. However, there is a lack of

fundamental understanding of such diverse interfaces. In addition, experimental techniques generally have practical objectives, such as the achievement of sufficient strength to sustain mechanical or thermal effects and/or have the proper electronic properties. In addition, the theoretical description of binding at interfaces is quite limited, and a proper data base for such theoretical analysis does not exist.

This presentation will review both experimental and theoretical aspects of adhesion in nonpolymer materials. The objective will be to delineate the critical parameters needed, governing adhesion testing along with an outline 
of testing objectives. A distinction will be made between practical and fundamental objectives. Examples will be given where interfacial bonding may govern experimental consideration. The present status of theory will be presented along with some recommendations for future progress and needs.

\section{INTRODUCTION}

The nature of inter-surface bonding forces is of general importance in fracture mechanics, tribology, adhesion of films, grain boundary energies, etc. The ability to determine these forces theoretically and experimentally has been limited. The reasons for these limitations involve the difficulties both in performing theoretical calculations and meaningful experiments. The interface problem is further complicated by the materials involved. Considering metals, semiconductors, ceramics, ionic solids, and polymers, and all of the possible combinations of these materials to be studied along with the differences in material properties within a class, the quantity of information necessary to characterize the interfaces multiplies rapidly. In this paper, we will discuss both the experimental and theoretical difficulties in obtaining basic information about bonding forces. Some experimental results which relate directly to surface bonding and recent calculations related to such forces will be presented.

\section{CONSIDERATIONS FOR EXPERIMENTS}

Surveys of experimental techniques for measuring adhesion are given in Refs. 1 to 3 . We first make a distinction in considering interfacial forces by defining two categories designated as "practical" adhesion and "fundamental" adhesion (Refs. 4 and 5). By practical adhesion, we mean that the application determines the needs; that is, in a practical situation, one may have a requirement that an interface be able to withstand mechanical stresses or thermal cycling. Consequently, a test must be developed wich simulates the 
conditions to be experienced, and a simple fail rate is the primary consideration. The purpose in fundamental adhesion is to design an experiment which measures the strength of the bonding force at an interface. In Table I, we give some criteria for defining the two types of tests as defined by Hitch (Ref. 5). To accomplish either type measurement is quite complicated, but to determine the fundamental adhesion properties is extremely complicated. In Table II, we give a list of experimental techniques for measuring practical adhesion. As an example of some of the difficulties involved in the measurement of fundamental adhesion, we will discuss a particular technique used in many fundamental studies. In this technique, one loads a field ion microscope (FIM) tip against a flat surface and then pull them apart to measure the bonding force. Other geometries have been used, but the discussion to follow is still applicable and illuminates some of the difficulties involved in performing adhesion tests. In order to simplify the discussion, let us assume that only the tip can deform. This particular experiment can be thought of in terms of a stress-strain diagram in a tensile test (Fig. i). We can see (Fig. $1(b)$ ) that if there is adhesion and elastic deformation, only, the stress-strain curve would show a simple Hooke's law behavior. Adhesion causes an additional deformation, and a negative load is needed to separate the surfaces. If the adhesive bonding force is stronger than the bulk, then ductile extension will occur before fracture, and the fracture will occur in the weaker of the two materials. Consequently, the measured forces are a complex combination of deformation and bonding if separation occurs at the interface. If it does not occur at the interface, one obtains no quantitative information other than that the interface was stronger than the bulk. Indeed, even establishing where separation has occurred is not simple and may require surface analysis to determine the locus of failure. If we add the 
complexities, such as multiple asperity contacts, varying material properties, or adsorbates, combined with the fact that the stress distribution in the contact zone is not uniform, we see that the interpretation of such experiments in terms of "fundamental" bonding forces becomes rapidly more complicated. Such pull tests, applied to a deposited film, suffer from many of the same difficulties.

We have seen that the interpretation of contact experiments is complicated. Determination of the strength of interfaces formed by deposition or by bonding techniques such as welding suffers from similar difficulties. In Table III, we outline some considerations which affect the interpretation of such experiments. Clearly, the range of considerations makes the connection to the fundamental strength of the interface tenuous, and also makes it questionable whether the film strength requirements for some practical applications can be attained. In addition to the limitations in testing techniques and bulk properties, there are uncertainties concerning the interface. The interfacial region may not be sharp; i.e., the composition may be graded. It may be sharp, but there may be segregation from the bulk, e.g., grain boundary segregation. The interface may have defects, a lattice mismatch, or even a lack of any long-range order. It is possible to have macroscopic defects, such as voids. Consequently, the measurement of interfacial strength requires a complex combination of test equipment, geometry, composition, binding forces, and material properties.

We now present some experimental results where the effects of adsorbates on interfacial forces have been investigated. In Fig. 2 , we show the results of measuring the adhesive (pull-off) force for a tungsten FIM tip in contact with clean versus oxide-covered nickel (Ref. 6). The presence of the oxide decreased the adhesive force. Wheeler (Ref. 7) Derformed interfacial shear 
experiments (coefficient of static friction) with a sphere-on-flat configuration with iron and copper couples with adsorption. He found a reduction in shear strength with both oxygen and chlorine adsorption (Fig. 3 ). In this experiment, his concentrations represent partial monolayer coverages rather than oxides. Pepper (Ref. 8) has performed similar experiments with metal insulator contacts (Fig. 4). First, in contacts between the metal and sapphire, the shear strength varied with metal. Next, the adsorption of chlorine on the metal, even at partial monolayer coverages, reduced the interfacial shear strength. Surprisingly, the adsorption oxygen on the metal increased the interfacial shear strength. Similarly, a single crystal diamond surface which could be modified by heating gave similar results (Ref. 9). Pepper has shown that heating removes hydrogen, which terminates the surface bonds. Removal of the hydrogen produces an increase in the interfacial shear strength. Replacing the hydrogen again reduces the shear strength. A more significant result is that the shear strength could be correlated to changes in the electronic structure, although a direct connection with physical models has not been made. These results are particularly important. In spite of the previous caveats presented about the difficulty in obtaining fundamental information from experiment, they show that modification of the interface with only partial monolayers gives detectable changes in interfacial bonding. This result then gives theoreticians a basis for modeling calculations based on bonding forces, with the ability to predict at least trends in experimental results.

A recent development (Ref. 10), the atomic force microscope, enables the measurement of the interfacial bonding force as a function of separation. The equipment is essentially a scanning-tunnelling microscope attached to a "spring." It is not unlike the FIM tip experiments with ability to measure the 
force before contact with high spatial resolution (bulk interplanar distances). A further development of this technique also permits mapping of the shear force (Ref. 11), thus permitting the possibility of mapping energy surfaces. The fact that these new techniques also give details of the binding curve--which will be discussed later--also gives more detailed data for comparison with theory. The other techniques discussed give at best only a maximum bonding strength or a change in this strength with adsorption. This technique also has some limitations; however, first, the geometry is not a flat-on-flat interface, and second, there are some material limitations. Current speculation indicates that the STM tip consists of one atom, or at most a small group of atoms, at the tip end participating in the interaction. The tip materials must be conductors. These are relatively minor limitations, however, and the technique should give quantitative data for comparison with theory.

Finally, we would like to discuss a technique which can give bonding information on thin films, which would be of more practical interest. In this method, developed by Vossen (Ref. 12), a number of dots of the film of interest are first deposited on a substrate, and then the other side of the substrate is exposed to a pulse from a laser. A shock wave created by the laser pulse, if of sufficient power, causes spallation of the film. Figure 5 shows a correlation between threshold energy density to remove a film of metal from an $\mathrm{SiO}_{2}$ substrate versus the heat of formation of the oxide. This technique has some hope of giving bond energies between interfaces. It has the advantage of being nondestructive to the couple, but is material limited. Material limitations are secondary at this stage, since it is necessary to build a data base from which to formulate theoretical models.

At this point, there is a great need for creativity in designing experiments to generate fundamental information about interfacial bonding. 
Also, there is a need for a reliable data base from which to formulate and test theories.

\section{THEORETICAL CONSIDERATION}

In the preceding sections, we discussed two types of interfacial motion: that perpendicular to the surfaces (tensile) and lateral motion (shear). For tensile forces, i.e., separation of the material normal to a plane, we expect the binding energy versus separation curve to have the shape shown in Fig. 6 . The well depth represents the binding energy; this is the surface energy for perfectly matched, identical half-spaces. The rise in the curve for separations less than the equilibrium value represents compression. The derivative of this curve is the force (actually the tensile stress) necessary to separate the surfaces. The maximum in this curve is the "breaking force," and it occurs at the inflection point of the binding energy curve. This is the simplest representation of what occurs experimentally and can be thought of as a brittle fracture curve. In ductile solids in tension, there would be a "stretching" or ductile extension before the brittle fracture. However, because of the complexity of a real tensile test, it is necessary to understand these components of the process individually.

The comparable plots for tangential motion would be represented by sliding one half-space over the other (Fig. 7). In this case, we have a potential barrier to overcome, where the top of this barrier is the amount of energy to be supplied to move to this position. Again, the maximum in the derivative of this curve gives the maximum force needed to cause slip and is at the inflection point of the energy barrier plots. In this case, the energies and forces are periodic and are often represented by periodic functions, e.g., the Frenkel model (Ref. 13). Again, in experiments, we have a more complex situation. This mechanism is conservative; i.e., the energy needed to place 
the solid at the top of the potential hill is regained in moving to the next symmetry position. In real processes, loss mechanisms are involved, such as plastic deformation or heating of the solids, giving rise to frictional forces.

There are further complexities involved at interfaces, even for close to the ideal case. If the structure deviates from the perfect symmetry of a plane in a bulk material, then a rearrangement will occur at the interface. If we bring two different planes of the same material together, or even have a rotation in a given plane (such as a twist grain boundary), there will either be a relaxation to some minimum energy configuration or strains at the interface. Obviously, the same considerations apply for two different materials in contact. Note that these considerations do not even approach the complexities of a graded interface.

Next we present some theoretical approaches to the interface problems. The interface poses a difficult problem for the solid-state theorist. Most techniques in solid-state calculations rely on the periodicity of the lattice to simplify the calculations (Ref. 14). This periodicity is lost at interfaces; consequently, special approaches are needed to handle these problems. The theoretical models used depend on the materials comprising the interface. For example, at free-electron metal interfaces, binding may not be localized, whereas at transition metal, semiconductor, or ceramic interfaces, we might expect localized bonding to be important. Pair potentials are often used to represent nonmetals (Ref. 15). In this method, the interaction between atoms is approximated by some two-body potential, e.g., a Van der Waals potential, and the energetics are obtained by establishing the geometry of the defect and summing over two-body interactions. For metals, this approach is not sufficient, because of the mobility of the electrons which redistribute their positions in the vicinity of a defect. Smith and Ferrante (Ref. 16) 
have estimated this electron redistribution contribution to the grain boundary energy for simple metals and have shown it to be large compared to pair potential contributions. There are attempts to include these volume-dependent contributions into a pair potential (Ref. 17); however, a question arises concerning how well these can represent complicated defect structures. Another fully quantum mechanical approach used for these situations involves Green's Function (Ref. 17) or tight-binding methods (Refs. 18 and 19). These approaches have been used recently to calculate grain boundary energies in semiconductors.

Fully quantum mechanical calculations of grain boundary energies are quite complex (Refs. 20 to 22 ) and require substantial computer time. Defects are included by constructing super cells using periodic boundary conditions. In order to examine relaxation, which occurs in most defect structures, it is necessary to repeat the calculation many times for different structures, in order to search for energy minima. This further adds to the complexity of the problem. Applying such techniques to molecular dynamics in order to include dynamic or temperature effects further complicates the calculations. Recently, Car and Parrinello (Ref. 23) have developed a technique to optimize the search for energy minima, but the procedure still remains quite complex. Thus, it would be useful to develop semi-empirical techniques for calculating defect energetics which have the simplicity of pair potentials but include the volumedependent effects. We will address this question shortly, but first we will present some calculations of interface or adhesion energies. Actually, there has been a paucity of such calculations. The only quantum mechanical calculations of the binding energy as a function of separation have been those performed by Ferrante and Smith (Ref. 24) for simple metal contacts. The 
calculations used a one-dimensional jellium model corrected for threedimensional effects. The adhesion energy was defined as

$$
E_{A D}=\frac{E(a)-E(\infty)}{2 A}
$$

where $E$ is the total energy of the system, a is the separation distance between the surfaces of the two metals, and $A$ is the cross-sectional area. The results of this calculation for the high-density surfaces of a number of simple metals in contact are shown in Fig. 8. Relaxation was not included in this calculation, with both materials frozen at their bulk structures. We see that the binding curves have the general shape expected. The strength of the interfacial bond was quite high, comparable to surface energies of the bulk materials, and the range was of the order of interplanar spacings. Rose, Smith, and Ferrante (Ref. 25) found that these curves scaled (Fig. 9); i.e., the energy could be written in a form

$$
E=\Delta E E^{*}\left(a^{*}\right)
$$

where $a^{*}=\left(r-r_{e}\right) / 1, \Delta E$ is the binding energy, $r_{e}$ is the equilibrium separation, and 1 is a scaling length to be discussed later. $E^{*}\left(a^{*}\right)$ is the functional form for some "universal" shape of these curves. Smith, Gay, Richter, and Arlinghaus (Ref. 26) have calculated surface energies for transition metal interfaces using a fully three-dimensional model and have obtained good agreement with experimental surface energies. They also calculated the electronic distribution for an interface between two transition metals. This situation is quite different from the simple metal interface, because of the localized nature of the d-bonding, and therefore the jellium approximation could not be used for these metals. Electron density difference plots at the different metal interfaces showed the localized nature of the bonding. 
Rose, Smith, and Ferrante (Ref. 25) showed that the scaled relation (Eq. (3)) for simple metals was more general than at first anticipated, and in fact, the scaling applied to a wider class of phenomena. In Fig. 10, we show the results of scaling cohesive energies for a transition metal, bimetallic adhesion, chemisorption, and a diatomic. A more important result in the present discussion, however, is that the cohesive energies of metals scale. The scaling length selected for all of these cases is given by

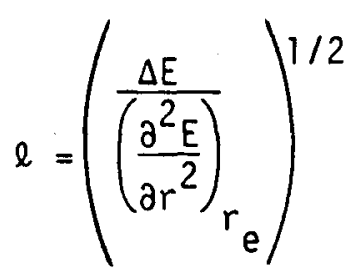

i.e., the square root of the equilibrium binding energy divided by the second derivative of the binding energy with separation evaluated at the equilibrium position. This particular--but not necessary--form for the length scaling is convenient, since the second derivative can be related to experimentally measurable properties, such as the bulk modulus for solids.

These results lead us finally to the discussion of the semi-empirical techniques needed to model interfaces and defects. The first technique is the embedded atom method of Foiles, Daw, and Baskes (Ref. 26), based on the effective medium theory of Norskov and Lang (Ref. 27) or the quasi-atom method of Stott and Zaremba (Ref. 28). In this procedure, the energy required to embed an ion in a jellium is considered. The total energy is written in the form

$$
E=F(n)+Z_{A}(R) Z_{B}(R) / R
$$

where $F(n)$ is called the embedding energy where $n$ is the electron density, and the second term represents the pair repulsion between ion cores where $Z(R)=Z_{0}(1+\beta R \nu) \exp (-\alpha R), Z$ is a nuclear charge, $R$ is the inter-ion distance, and $\beta, \nu$, and $a$ are determined from fitting to experiment. In its 
most recent form, the "universal" binding energy relation of Rose, Smith, and Ferrante is used to define the embedding energy for the cohesive energy case. The electron density is obtained from overlapping atomic densities. Once the embedding function is obtained, it is applied to a defect, such as a surface, by overlapping the atomic densities and using the embedding function for the given material, along with the pair repulsion term, to obtain the energy with a defect. The parameters in the equation are obtained from fits to experiment, such as vacancy energies or shear strength. The present authors have applied these techniques to the adhesion between three planes of $\mathrm{Ni}$ (Fig. 11) and for slip on two planes of $\mathrm{Ni}$ (Fig. 12). The results give the correct trends and shapes for the energy curves in both cases. The methods have been successfully applied to a large number of defects and have been extended to include alloys and nonmetals. It is substantially simpler than the solid-state techniques described earlier.

The next method we wish to describe is the equivalent crystal method of Smith and Banerjea (Refs. 29 and 30]. This technique also uses the universal binding energy relations. In this technique, an ion in a defect is represented by a position in a perfect crystal with a structure the same as bulk material. Perturbation theory is applied to the difference between the ion in the defect and the ion in the equivalent crystal, giving

$$
E=\Delta E E^{*}\left(a^{*}\right)+E_{1}+E_{2}+E_{3}+\cdots \cdot
$$

where the first term represents the energy of the atom in the crystal, and the rest of the terms represent the difference in ion core-ion core interaction, valence electron kinetic energy, valence electron-ion core interaction, and valence electron-valence electron interaction between the crystal and the solid with defects. The problem is solved by picking the Wigner-Seitz radius (Ref. 14) used in defining the distance in $a^{*}$ to make the higher order terms 
in the perturbation expansion disappear. With this accomplished, only the first simple term need be evaluated. This approach also represents a great simplification over quantum mechanical models. In Table IV, we show a comparison between the predictions of surface energies for this calculation, fully three-dimensional quantum mechanical calculations, experiment, and the embedded atom method. We see remarkable agreement with the fully quantum mechanical models. We note that experimental surface energies are extremely difficult to measure and are good to only \pm 20 percent at best. Smith and Banerjea (Ref. 30) have altered the model slightly to include a bond compression term in order to include surface relaxation. Table $V$ presents the results of comparison of this method with experiment. These results are particularly impressive, since they represent small energy differences. These are very difficult to obtain accurately from the quantum mechanical calculations. It is necessary to extend this method to a wider class of materials. This extension and application to a number of defects is in progress (Ref. 31). We point out that the fully quantum mechanical calculations are still needed, since many properties cannot be calculated with the semi-empirical methods and also as a test of the semi-empirical methods. Both this method, and the embedded atom method, are simple enough to treat relaxation problems.

In summary, although experimental measurements which reveal fundamental information about bonding at interfaces remains difficult, theory has made considerable progress. Both fully quantum mechanical calculations and semiempirical nethods are now successfully being applied to interface and defect energetic problems successfully. The new, semi-empirical techniques are simple enough to be used by nonspecialists in quantum theory calculations. The accuracy of the prediction by the equivalent crystal method gives hope that 
substantial progress will be made in prediction of interface and defect energies. Possibly these results will serve us and aid experimentalists in sorting out the many factors with which they must deal.

\section{REFERENCES}

1. D.H. Buckley, Surface Effects in Adhesion, Friction, Wear and Lubrication, Elsevier, Amsterdam, 1982.

2. K.L. Mittal Ed., Adhesion Measurement of Thin Films, Thick Films and Bulk Coatings, ASTM Special Publication 640, ASTM, Philadelphia, 1978.

3. J.R. Smith, Editor, Mat. Sci. Engineering 83, 169-234 (1986), Panel Report on Interfacial Bonding and Adhesion, Aspen, Co., U.S.A., Aug. 11-16, 1985.

4. D.M. Mattox and D.A. Rigney, Ibid Ref. 3, p. 189; D.M. Mattox Ibid Ref. 2, p. 54 .

5. T.T. Hitch, Ibid Ref. 2, p. 211.

6. M.D. Pashley and D. Tabor, Vacuum 31, 619 (1981).

7. D.R. Wheeler, J. Appl. Phys. 47, 1123 (1976).

8. S.V. Pepper, J. Appl. Phys. 50, 8062 (1974); J. Appl. Phys. 47,2579 (1976).

9. S.V. Pepper, J. Vac. Sci. Tech. 20, 643 (1982).

10. G. Binnig, C.F. Quate, and Ch. Gerber, Phys, Rev. Lett. 56, 930 (1986).

11. C.M. Mate, G.M. McClelland, R. Erlandsson, and S. Chiang, Phys. Rev. Lett. 59, $1942(1987)$.

12. J.L. Vossen, Ibid Ref. 2, p. 122.

13. C. Kittel, Introduction to Solid State Physics, 3 ed., John Wiley and Sons, New York, 1966.

14. N.W. Ashcroft and N.D. Mermin, Solid State Physics, Holt, Rinehart and Winston, New York, 1976.

15. D.R. Clarke and D. Wolf, Ibid Ref. 2, p. 197. 
16. J.R. Smith and J. Ferrante, Phys. Rev. B 34, 2238 (1986).

17. A. Yaniv, Phys. Rev. B 17, 3904 (1978).

18. G. Allan, M. Lannoo, and L. Dobrzynski, Phil. Mag. 30, 33 (1974).

19. C.C. Pei, Phys. Rev. B 18, 2583 (1978).

20. M.C. Payne, P.D. Bristowe, and J.D. Joannapoulos, Phys. Rev. Lett. $\underline{58}$, $1348(1987)$.

21. D.P. DiVincenzo, O.L. Alehand, M. Schluter, and J.W. Wilkins, Phys. Rev. Lett. $\underline{56}, 1925(1986)$.

22. R.E. Thomson and D.J. Chadi, Phys. Rev. B 29, 889 (1984).

23. R. Car and M. Parrinello, Phys. Rev. Lett. 55, 2471 (1985).

24. J. Ferrante and J.R. Smith, Phys, Rev. B 31, 3427 (1985).

25. J.H. Rose, J. Ferrante, and J.R. Smith, Phys. Rev. Lett. 47, 675 (1981); J.R. Smith, J. Ferrante, and J.H. Rose, Phys. Rev. B 25, 1419 (1982);

J. Ferrante, J.R. Smith, and J.H. Rose, Phys. Rev. Lett. 50, 1385 (1983); J.R. Smith, J.H. Rose, J. Ferrante, and F. Guinea, Many Body Phenomena at Surfaces, D. Langreth and H. Suhl, eds., Academic Press, New York (1984); P. Vinet, J. Ferrante, J.R. Smith, and J.H. Rose, J. Phys. C 19, L467 (1986).

26. S.M. Foiles, M.I. Baskes, and M.S. Daw, Phys. Rev. B $\underline{33}, 7983$ (1986), and Refs. Cited Therein.

27. J.K. Norskov and N.D. Lang, Phys. Rev. B 21, 2131 (1980).

28. M.J. Stott and E. Zaremba, 22, 1564 (1980).

29. J.R. Smith and A. Banerjed, Phys. Rev. Lett 59, 2451 (1987).

30. J.R. Smith and A. Banerjea, To be Published J. Vac. Sci. Tech.

31. J. R. Smith, Private Communication.

32. D.S. Campbe 11, Handbook of Thin Film Technology, Ed. G.I. Maissel and R. Gland, Chap. 12, McGraw-Hill Book Co., New York, 1970. 
TABLE I. - ADHESION TESTS [5]

Fundamental

Useful over a wide range of materials.

Quantitative, reproducible over a wide range of adhesion strengths

Not influenced by other material parameters.

Allows direct measurement of adhesion strengths as distinct from other parameters.

Practical Adhesion Tests

Qualitative or threshhold tests--not designed to quantify adhesion strength. Just designed to set bounds on whether adhesion is greater than some often 111 -defined limiting strength.

Quantitative tests--quantitative but not ideal values for adhesive strength are obtained, but with the purpose of satisfying some known engineering bound on the strength.

TABLE II. - ENGINEERING TECHNIQUES FOR MEASURING ADHESION [Ref. 32]

\begin{tabular}{|c|c|}
\hline Method & Principle \\
\hline $\begin{array}{l}\text { Bending } \\
\text { Squashing } \\
\text { Abrasion } \\
\text { Heating and quenching }\end{array}$ & $\begin{array}{l}\text { Substrate bent or twisted until film removed } \\
\text { Substrate squashed until film removed } \\
\text { Burnishing or abrasion of surface to remove film } \\
\text { Heating and sudden quenching will cause film to } \\
\text { be removed because of stresses developed by } \\
\text { thermal expansion and contraction }\end{array}$ \\
\hline Scratching & $\begin{array}{l}\text { Film scratches through by probe. Alternatively } \\
\text { parallel grooves cut into the film with } \\
\text { decreasing separation until intervening } \\
\text { material lifts from substrate }\end{array}$ \\
\hline Hammering & Hammering breaks up and removes film \\
\hline Indentation & $\begin{array}{l}\text { Substrate indented from side opposite to film. } \\
\text { Coating examined for cracking or flaking off at } \\
\text { varlous stages of indent formation }\end{array}$ \\
\hline Pulling & $\begin{array}{l}\text { Film pulled off directly if it is thick enough. } \\
\text { If not, backing attached using: } \\
\text { Solder } \\
\text { Adhesives } \\
\text { Electroforming }\end{array}$ \\
\hline Peeling & $\begin{array}{l}\text { Film peeled off using a backing of: } \\
\text { Adhesive tape } \\
\text { Electroplated coating }\end{array}$ \\
\hline Deceleration & $\begin{array}{l}\text { The film and substrate are subject to violent } \\
\text { deceleration, which removes the film. Various } \\
\text { experimental arrangements are possible: } \\
\text { Coated bullet stopped by steel plate } \\
\text { Ultracentrifuge } \\
\text { Ultrasonic vibration }\end{array}$ \\
\hline Electromagnetic & $\begin{array}{l}\text { Applying a force to a conducting film by } a \underline{v} \times \underline{B} \\
\text { force }\end{array}$ \\
\hline $\begin{array}{l}\text { Shock wave } \\
\text { Blistering }\end{array}$ & $\begin{array}{l}\text { Pulsing the backface of a specimen with a laser } \\
\text { Film deposited so that no adhesion exists over a } \\
\text { particular area. Air is then introduced into } \\
\text { this area and the pressure at which film start } \\
\text { to lift from the edge of the area of no } \\
\text { adhesion is measured }\end{array}$ \\
\hline
\end{tabular}


TABLE III. - FACTORS AFFECTING ADHESION MEASUREMENTS

Adhesive Strength Depends

Geometry

Different tests cause nonuniform stress distributions, e.g., peel tests.

Discontinuities in shape or material can act as stress ralsers. Surface roughness increases surface area and applied forces are not necessarlly normal to the surfaces.

Test Machine

Stored stresses in apparatus can affect results, for example, by continuing to cause fracture or peeling.

Mechanical properties of the adherend or glue

Mechanical Properties of the couples: for example, hardness, ductility

Temperature

Strain rate

Instrinsic stress in deposited film are sufficient to cause delamination.

Defect Structure

Locus of fallure 
TABLE IV. - SURFACE ENERGIES FOR SOME SELECTED METALS

[In erg $\left.-\mathrm{cm}^{-2}.\right]$

\begin{tabular}{|c|c|c|c|c|c|}
\hline Element & $\begin{array}{l}\text { Crystal } \\
\text { face }\end{array}$ & $\begin{array}{c}E C M \\
(\operatorname{Ref} .29)\end{array}$ & $\begin{array}{l}\text { Theory } \\
\text { (LDA) }\end{array}$ & $\begin{array}{c}\text { EAM } \\
(\operatorname{Ref} .26)\end{array}$ & Experimenta \\
\hline $\mathrm{Al}$ & $\begin{array}{l}(111) \\
\text { poly } \\
(100) \\
(110)\end{array}$ & \begin{tabular}{r}
920 \\
\hdashline 1280 \\
1310
\end{tabular} & \begin{tabular}{l}
$-\cdots$ \\
\hdashline $1090^{6}$
\end{tabular} & $\begin{array}{l}-\cdots \\
-\cdots \\
-\cdots\end{array}$ & $\begin{array}{l}---- \\
1169 \\
-----\end{array}$ \\
\hline $\mathrm{Ni}$ & $\begin{array}{l}(111) \\
\text { poly } \\
(100) \\
(110)\end{array}$ & $\begin{array}{l}2400 \\
---- \\
3120 \\
2980\end{array}$ & $3050^{d}$ & \begin{tabular}{l}
$1450^{C} \mathrm{C}$ \\
\hdashline $1580^{\circ} \mathrm{C}$ \\
$1730^{\circ}$
\end{tabular} & $\begin{array}{l}--- \\
2664 \\
----\end{array}$ \\
\hline $\mathrm{Cu}$ & $\begin{array}{l}(111) \\
\text { poly } \\
(100) \\
(110)\end{array}$ & $\begin{array}{l}1830 \\
-2380 \\
2270\end{array}$ & $\frac{2100^{e}}{2300^{d}}$ & \begin{tabular}{l}
$1170^{C}$ \\
\hdashline $1280^{\circ}$ \\
$1400^{C}$
\end{tabular} & $\begin{array}{l}---- \\
2016 \\
-----\end{array}$ \\
\hline $\mathrm{Ag}$ & $\begin{array}{l}(111) \\
\text { poly } \\
(100) \\
(110)\end{array}$ & $\begin{array}{l}1270 \\
-1630 \\
1540\end{array}$ & $1650^{d}$ & $\begin{array}{r}620^{c} \mathrm{C} \\
705^{c} \\
770^{c}\end{array}$ & $\begin{array}{l}---- \\
1543 \\
---\end{array}$ \\
\hline $\mathrm{Fe}$ & $\begin{array}{l}(110) \\
\text { poly } \\
(100)\end{array}$ & $\begin{array}{l}1810 \\
-3490\end{array}$ & $3100^{d}$ & $\overline{1693 f}$ & 2452 \\
\hline$w$ & $\begin{array}{l}(110) \\
\text { poly } \\
(100)\end{array}$ & $\begin{array}{l}3330 \\
---- \\
5880\end{array}$ & 51009 & $\begin{array}{l}---- \\
2926^{f}\end{array}$ & 4435 \\
\hline
\end{tabular}

aH. Wawra, Z. Metallk. 66, 395, 492 (1975).

bK.M. Ho and K.P. Bohnen, Phys. Rev. B 32, 3446 (1985).

CS.M. Foiles et al., Phys. Rev. B 33, 7983 (1986).

dj.G. Gay et al., J. Vac. Sci. Technol. A 2, 931 (1984).

eJ.A. Appelbaum and D.R. Hamann, Solid State Commun. 27, 881 (1978).

fM.W. Finnis and J.E. Sinclair, Phil. Mag. A 50, 45 (1984).

gC.L. Fu et al., Phys. Rev. B 31, 1168 (1985). 
TABLE V. - PERCENTAGE CHANGES IN INTERLAYER SPACINGS DUE TO RELAXATION

\begin{tabular}{|c|c|c|c|c|c|}
\hline \multirow[t]{2}{*}{ Surface } & \multirow[t]{2}{*}{$\Delta d_{n, n+1}$} & \multicolumn{2}{|c|}{ Theory } & \multirow{2}{*}{$\begin{array}{l}\text { Experiment, } \\
\text { Percent }\end{array}$} & \multirow[t]{2}{*}{ Technique } \\
\hline & & $\begin{array}{l}\text { ECM, } \\
\text { Percent } \\
\text { [Ref. 30] }\end{array}$ & $\begin{array}{l}\text { EAMa } \\
\text { Percent }\end{array}$ & & \\
\hline AI (1ו) & $\begin{array}{l}\Delta d_{12} \\
\Delta d_{23}\end{array}$ & $\begin{array}{r}-3.6 \\
1.8\end{array}$ & ----- & ------ & - \\
\hline Al $(100)$ & $\begin{array}{l}\Delta d_{12} \\
\Delta d_{23}\end{array}$ & $\begin{array}{r}-5.0 \\
2.1\end{array}$ & --- & - & - \\
\hline$A \mid(110)$ & $\begin{array}{l}\Delta d_{12} \\
\Delta d_{23} \\
\Delta d_{34} \\
\Delta d_{45}\end{array}$ & $\begin{array}{r}-10.1 \\
4.8 \\
-.4 \\
.0\end{array}$ & - & $\begin{array}{r}-8.6 \pm 0.8 \\
-8.5 \pm 1.0 \\
5.0 \pm 1.1 \\
5.5 \pm 1.1 \\
-1.6 \pm 1.2 \\
2.2 \pm 1.3 \\
0.1 \pm 1.3 \\
1.6 \pm 1.6\end{array}$ & $\begin{array}{l}\text { Leed }^{b} \\
\text { Leed }^{c} \\
\text { Leed }^{b} \\
\text { Leed }^{c} \\
\text { Leed }^{b} \\
\text { Leed }^{c} \\
\text { Leed }^{b} \\
\text { Leed }^{c}\end{array}$ \\
\hline $\mathrm{Ni}(111)$ & $\begin{array}{l}\Delta d_{12} \\
\Delta d_{23}\end{array}$ & $\begin{array}{r}-2.9 \\
1.4\end{array}$ & $\begin{array}{r}0.05 \\
.00\end{array}$ & ---o-- & - \\
\hline $\mathrm{Ni}(100)$ & $\begin{array}{l}\Delta d_{12} \\
\Delta d_{23}\end{array}$ & $\begin{array}{r}-3.7 \\
1.7\end{array}$ & $\begin{array}{r}0.002 \\
.001\end{array}$ & ------ & - \\
\hline $\mathrm{Ni}(110)$ & $\begin{array}{l}\Delta d_{12} \\
\Delta d_{23}\end{array}$ & $\begin{array}{r}-6.8 \\
3.2\end{array}$ & $\begin{array}{r}-2.30 \\
.08\end{array}$ & $\begin{array}{r}-8.7 \pm 0.5 \\
-4.8 \pm 1.7 \\
3.0 \pm 0.6 \\
2.4 \pm 1.2\end{array}$ & $\begin{array}{c}\text { Leedd } \\
\text { Ion scatteringe } \\
\text { Leedd } \\
\text { Ion scatteringe }\end{array}$ \\
\hline
\end{tabular}

as.M. Foiles et al., Phys. Rev. B 33, 7983 (1986).

bj.N. Andersen et al., J. Phys. C: Solid State Phys. 17, 173 (1984).

CJ.R. Noonan and H.L. Davis, Phys. Rev. B 29,4349 (1984).

dD.L. Adams et al., J. Phys. C: Solid State Phys. 18, 1753 (1985).

$e_{R}$. Feldenhansl et al., Surf. Sci. 134, 329 (1983). 
TABLE V. - Concluded.

\begin{tabular}{|c|c|c|c|c|c|}
\hline \multirow[t]{2}{*}{ Surface } & \multirow[t]{2}{*}{$\Delta d_{n, n+1}$} & \multicolumn{2}{|c|}{ Theory } & \multirow{2}{*}{$\begin{array}{c}\text { Experiment, } \\
\text { Percent }\end{array}$} & \multirow[t]{2}{*}{ Technique } \\
\hline & & $\begin{array}{c}\text { ECM, } \\
\text { Percent } \\
\text { [Ref. 30] }\end{array}$ & $\begin{array}{l}\text { EAMa } \\
\text { Percent }\end{array}$ & & \\
\hline $\mathrm{Cu}(111)$ & $\begin{array}{l}\Delta d_{12} \\
\Delta d_{23}\end{array}$ & $\begin{array}{r}-2.8 \\
1.4\end{array}$ & $\begin{array}{r}-1.40 \\
-.05\end{array}$ & $-0.7 \pm 0.5$ & Leedf \\
\hline $\mathrm{Cu}(100)$ & $\begin{array}{l}\Delta d_{12} \\
\Delta d_{23}\end{array}$ & $\begin{array}{r}-3.5 \\
1.6\end{array}$ & $\begin{array}{l}-1.4 \\
-.3\end{array}$ & $\begin{array}{l}-2.1 \pm 1.7 \\
-1.1 \pm .4 \\
0.45 \pm 1.7 \\
1.7 \pm .6\end{array}$ & $\begin{array}{l}\text { Leedg } \\
\text { Leedh } \\
\text { Leedg } \\
\text { Leedh }\end{array}$ \\
\hline $\mathrm{Cu}(110)$ & $\begin{array}{l}\Delta d_{12} \\
\Delta d_{23}\end{array}$ & $\begin{array}{r}-6.5 \\
2.7\end{array}$ & $\begin{array}{r}-4.9 \\
.2\end{array}$ & $\begin{array}{l}-8.5 \pm 0.6 \\
-5.3 \pm 2.4 \\
2.3 \pm .8 \\
3.3 \pm 1.5\end{array}$ & $\begin{array}{l}\text { Leedp } \\
\text { Ion scattering } i \\
\text { Leedp } \\
\text { Ion scattering } i\end{array}$ \\
\hline $\mathrm{Ag}(111)$ & $\begin{array}{l}\Delta d_{12} \\
\Delta d_{23}\end{array}$ & $\begin{array}{r}-2.3 \\
1.1\end{array}$ & $\begin{array}{r}-1.30 \\
-.04\end{array}$ & $-\cdots$ & - \\
\hline $\mathrm{Ag}(100)$ & $\begin{array}{l}\Delta \mathrm{d}_{12} \\
\Delta \mathrm{d}_{23}\end{array}$ & $\begin{array}{r}-2.9 \\
1.4\end{array}$ & $\begin{array}{r}-1.90 \\
-.05\end{array}$ & - & - \\
\hline $\mathrm{Ag}(110)$ & $\begin{array}{l}\Delta d_{12} \\
\Delta d_{23}\end{array}$ & $\begin{array}{r}-5.4 \\
2.4\end{array}$ & $\begin{array}{r}-5.4 \\
.3\end{array}$ & $\begin{array}{c}-5.7 \\
-7.8 \pm 2.5 \\
2.2 \\
4.3 \pm 2.5\end{array}$ & $\begin{array}{c}\text { Leedh } \\
\text { Ion scatteringj } \\
\text { Leed }^{h} \\
\text { Ion scatteringj }\end{array}$ \\
\hline
\end{tabular}

fS.A. Lindgren et al., Phys. Rev. B 29, 576 (1984).

9R. Mayer et al., Phys. Rev. B 35, 3102 (1987).

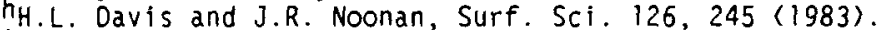

iD.L. Adams et al., Phys. Rev. Lett. 49,669 (1982).

jY. Kuk and L.C. Feldman, Phys. Rev. B 30, 5811 (1984). 


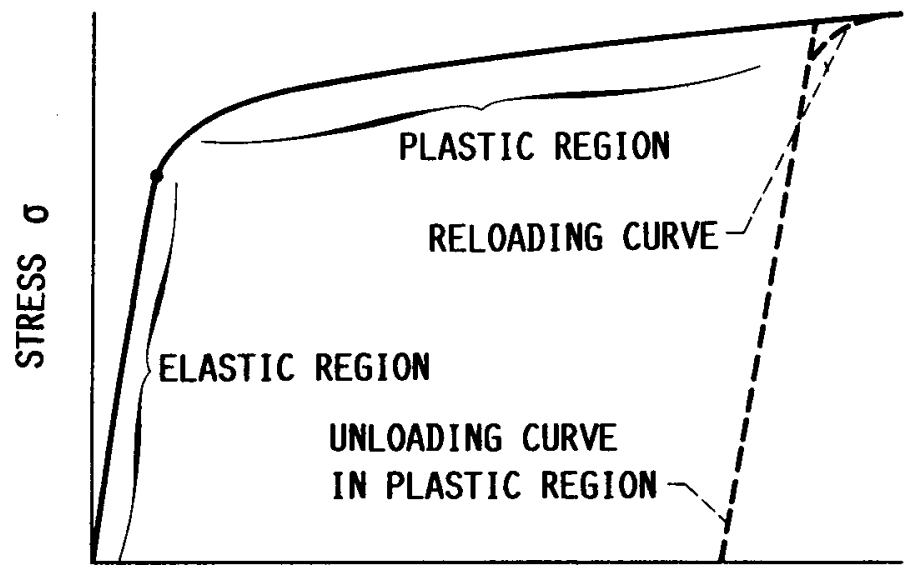

REAL STRAIN

(A) TYPICAL STRESS-STRAIN DIAGRAM.

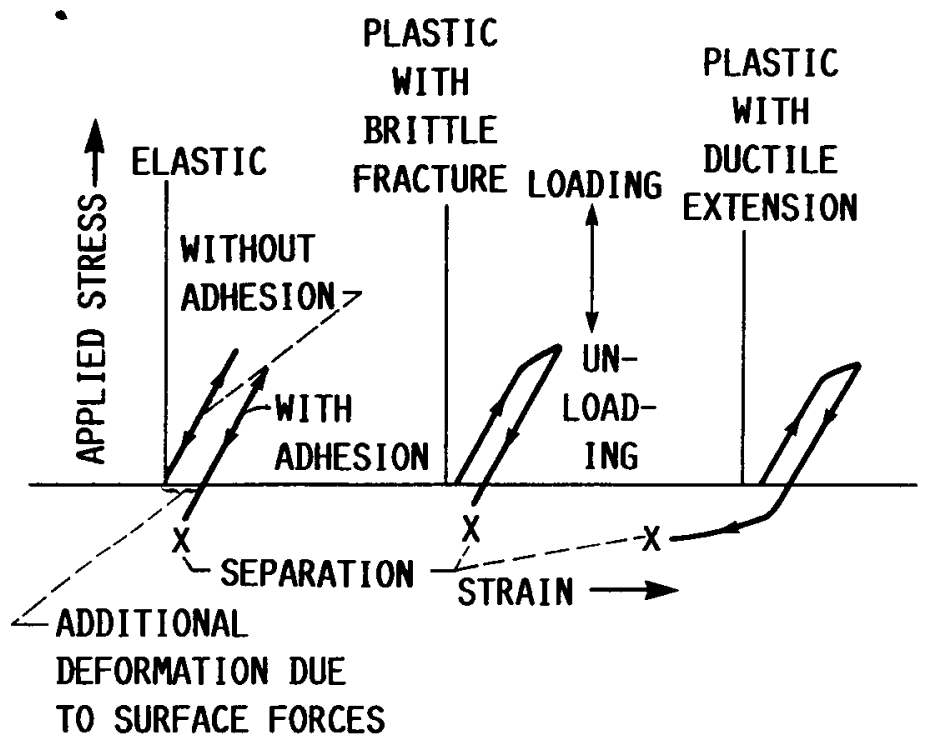

(B) LOADING AND UNLOADING STRESS-STRAIN CURVES WITH ADHESION (IDALIZED SINGLE CONTACT).

FIGURE 1. - STRESS-STRAIN DIAGRAM FOR A TENSILE TEST. 


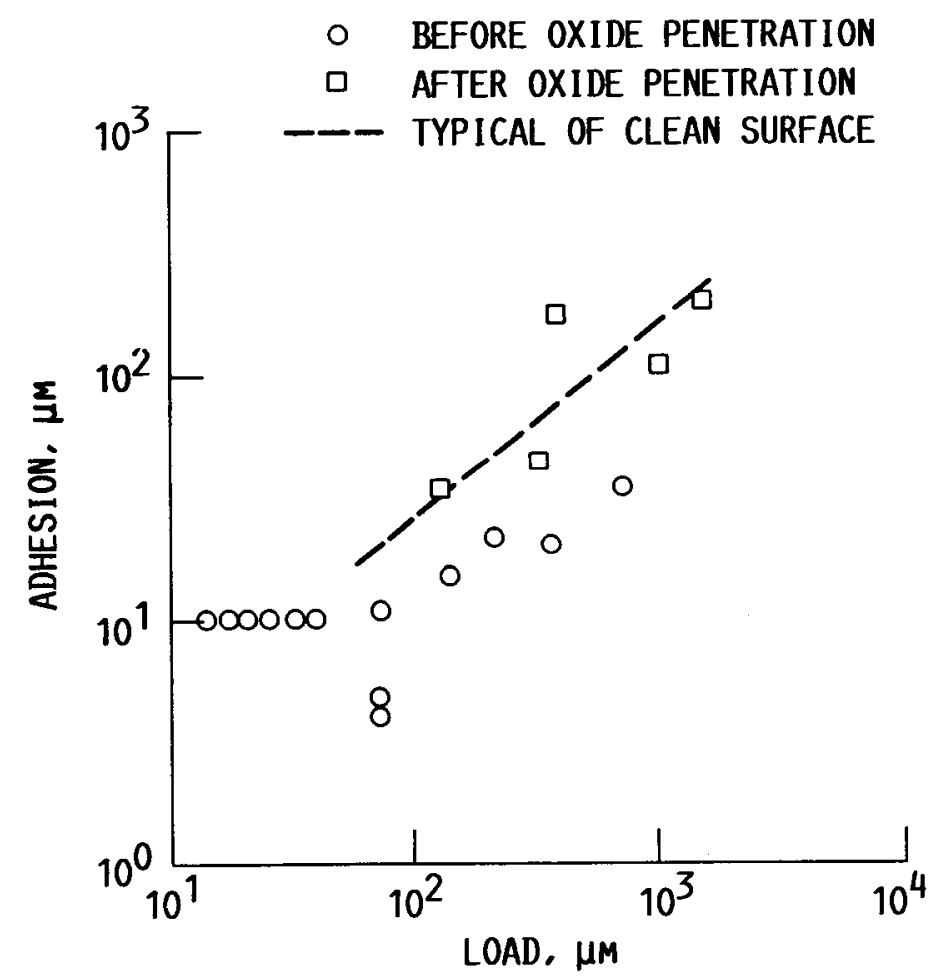

FIGURE 2. - ADHESION VERSUS LOAD WITH AN OXIDE FILM PRESENT FOR A TUNGSTEN FIELD EMISSION TIP ON A CLEAN AND OXIDIZED NICKEL. (FROM REF, 6.) 


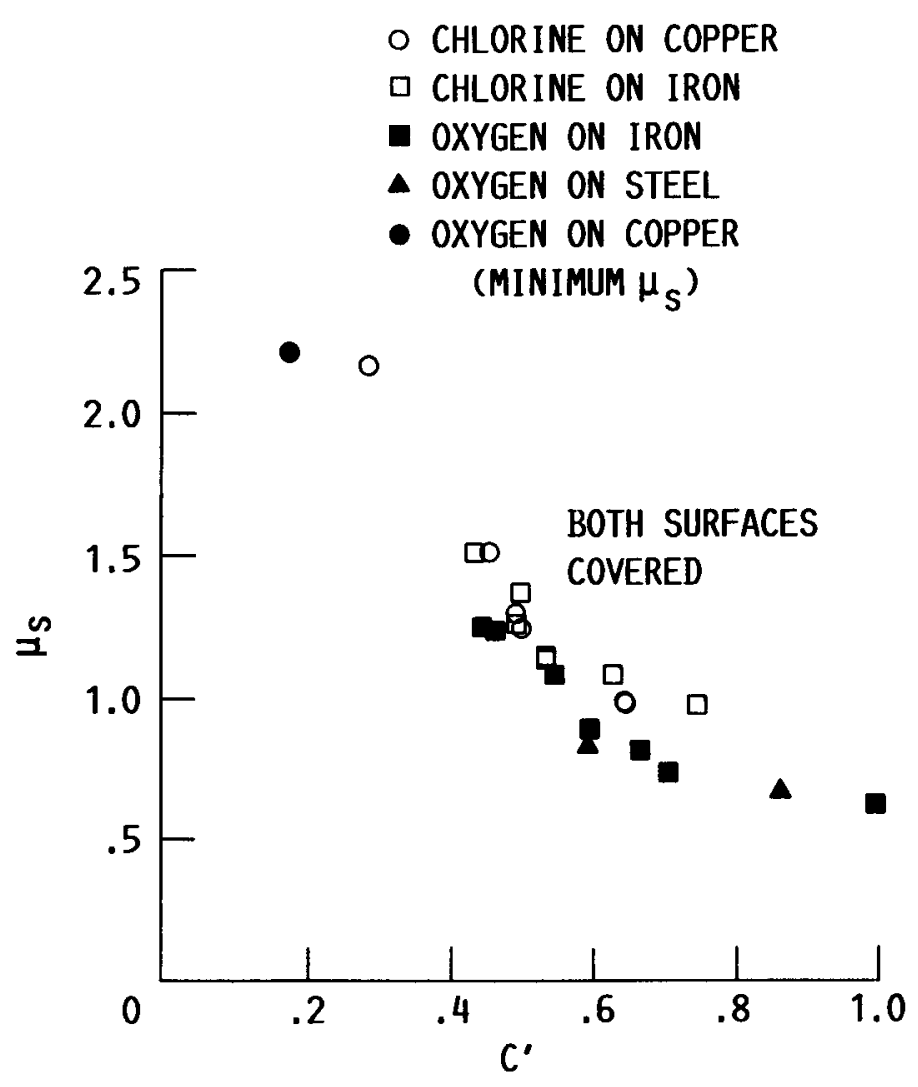

FIGURE 3. - EFFECTS OF OXYGEN AND CHLORINE ADSORPTION ON STATIC FRICTION FOR A METAL-METAL CONTACT AS A FUNCTION OF ADSORPTION COVERAGE. REF. 7. 


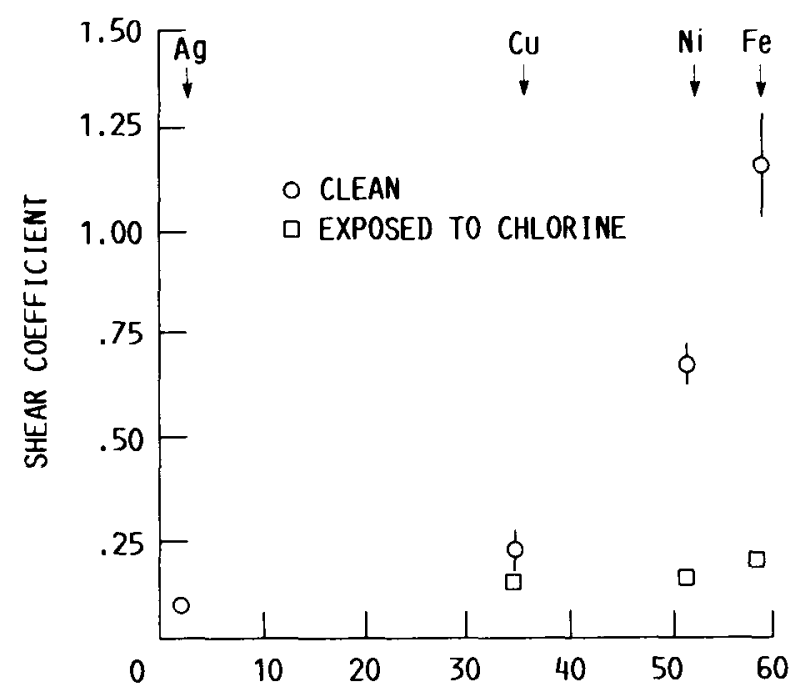

(A) PLOTTED VERSUS FREE ENERGY OF OXIDE FORMATION OF THE LOWEST METAL OXIDE.
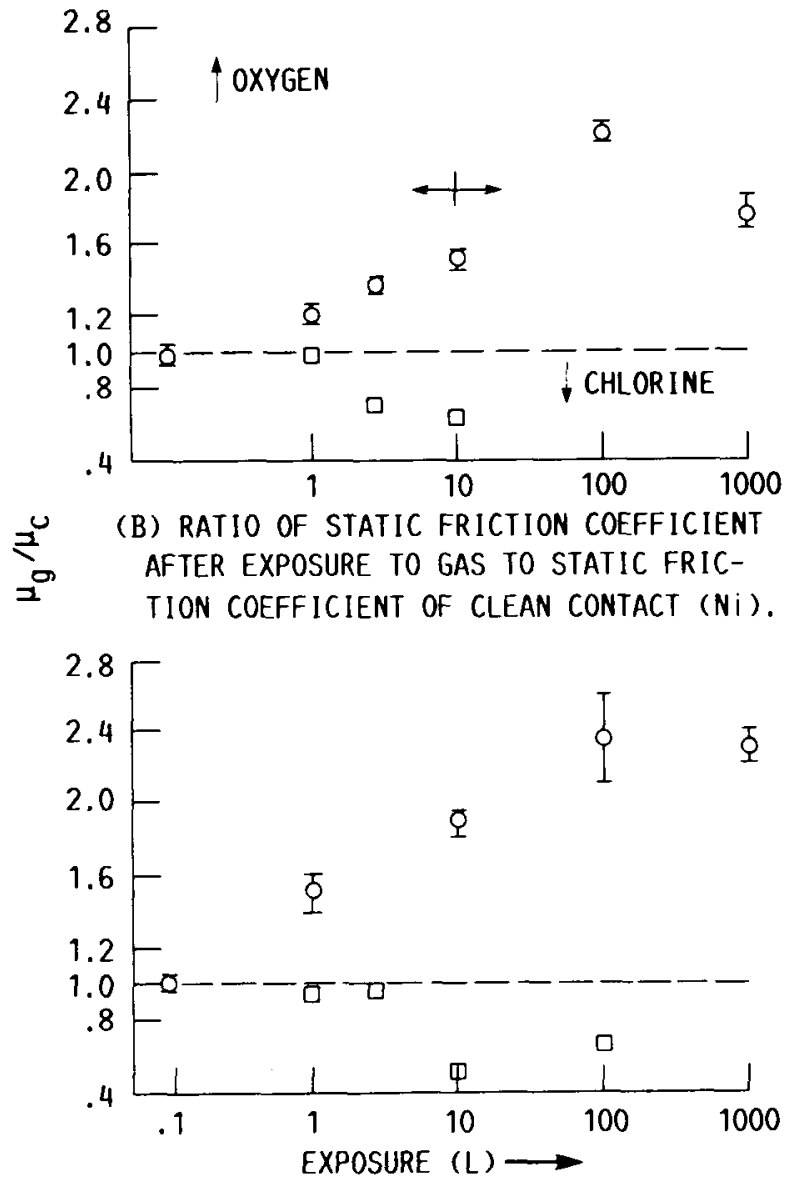

(C) RATIO OF STATIC FRICTION COEFFICIENT AFTER EXPOSURE TO GAS TO STATIC FRICTION COEFFICIENT OF CLEAN CONTACT (CU).

FIGURE 4. - SHEAR COEFFICIENT OF CLEAN. CHLORINATED AND OXYGENATED METALS IN CONTACT WITH CLEAN (0001) SAPPHIRE REF. 8. 


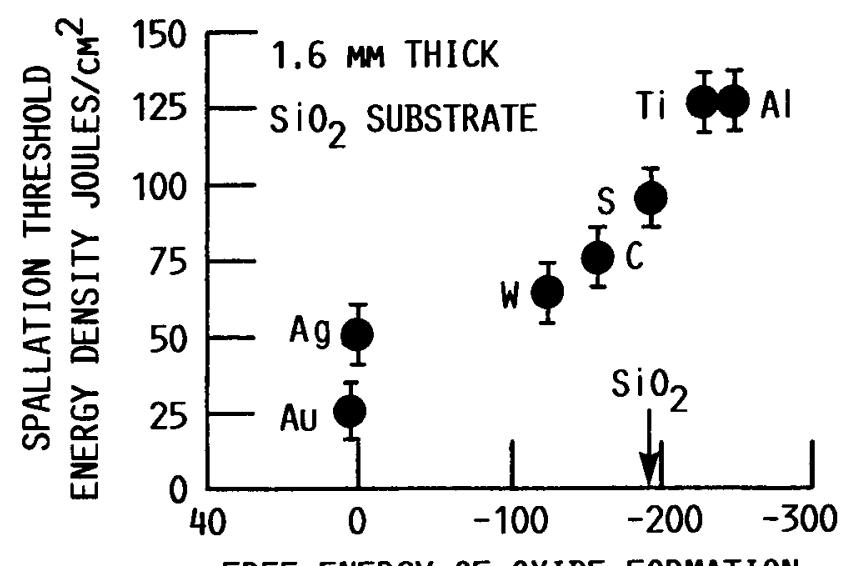

FREE ENERGY OF OXIDE FORMATION, KCAL/MOLE

FIGURE 5. - SPALLATION THRESHOLD FOR VARIOUS METAL FILMS DEPOSITED ON FUSED SILICA SUBSTRATES. ENERGY DENSITY IS THAT WHICH IS INCIDENT ON THE BACK SIDE OF THE SUBSTRATE, NOT ENERGY DENSITY AT INTERFACE. REF. 12.

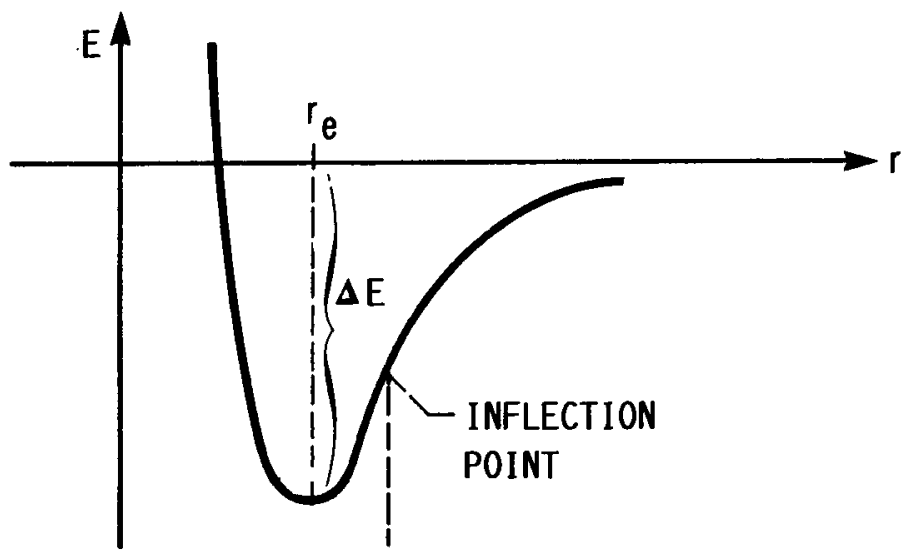

(A) ENERGY VERSUS SEPARATION.

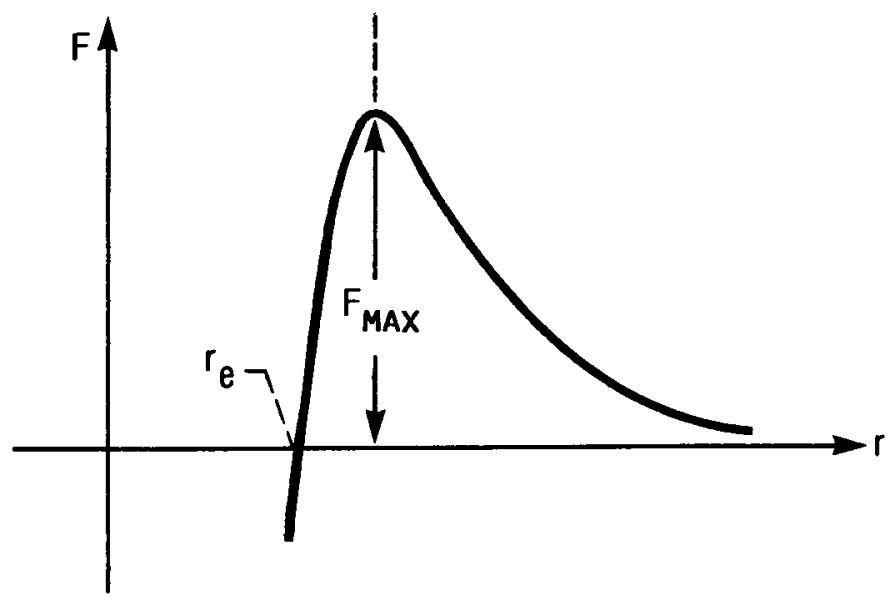

(B) FORCE VERSUS SEPARATION.

FIGURE 6. - EXAMPLE OF BINDING ENERGY CURVE. 


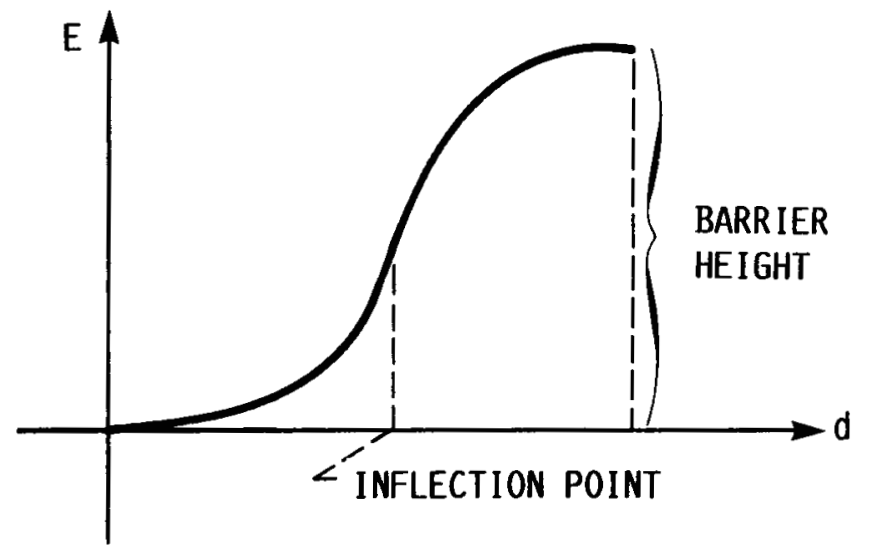

(A) ENERGY VERSUS DISPLACEMENT.

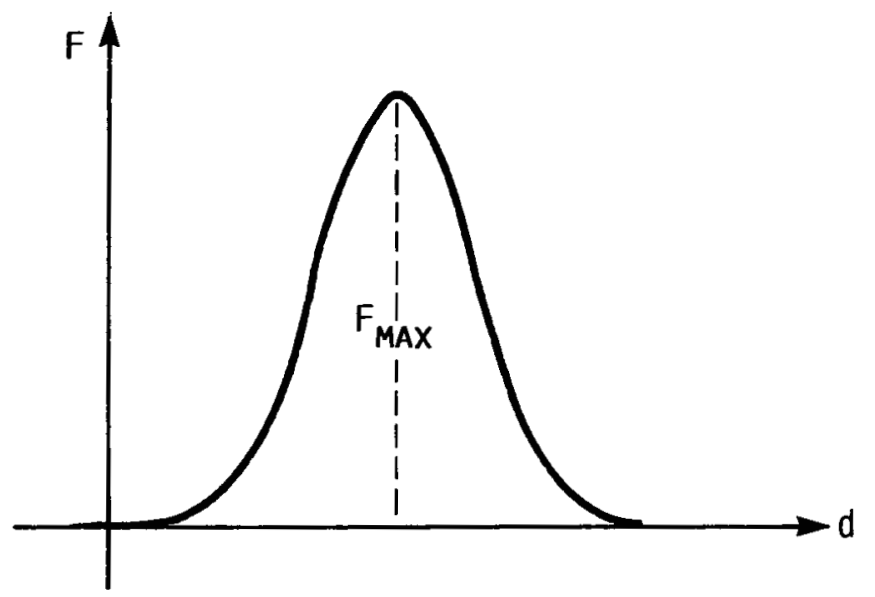

(B) FORCE VERSUS DISPLACEMENT.

FIGURE 7. - EXAMPLE OF ENERGY BARRIER TO SLIP. 


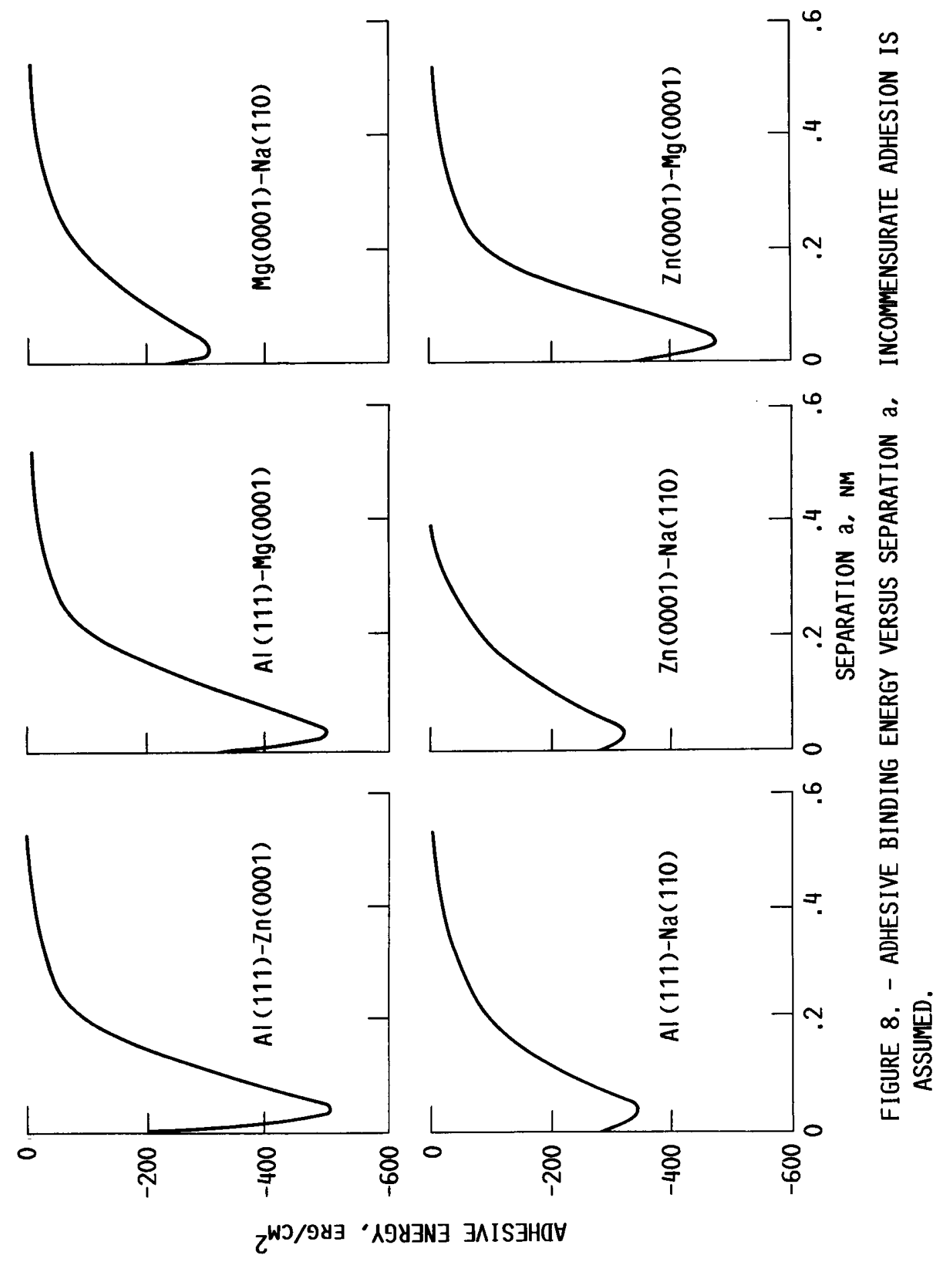




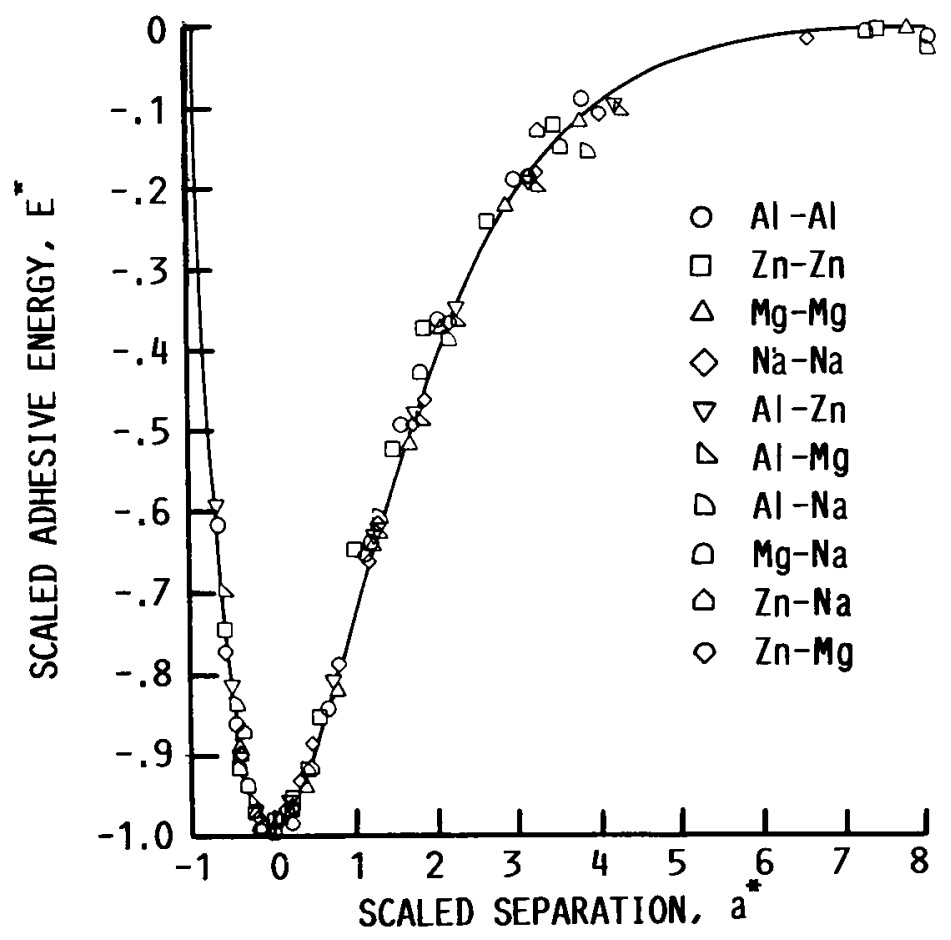

FIGURE 9. - SCALED ADHESIVE BINDING AS FUNCTION OF SCALED SEPARATION ENERGY.

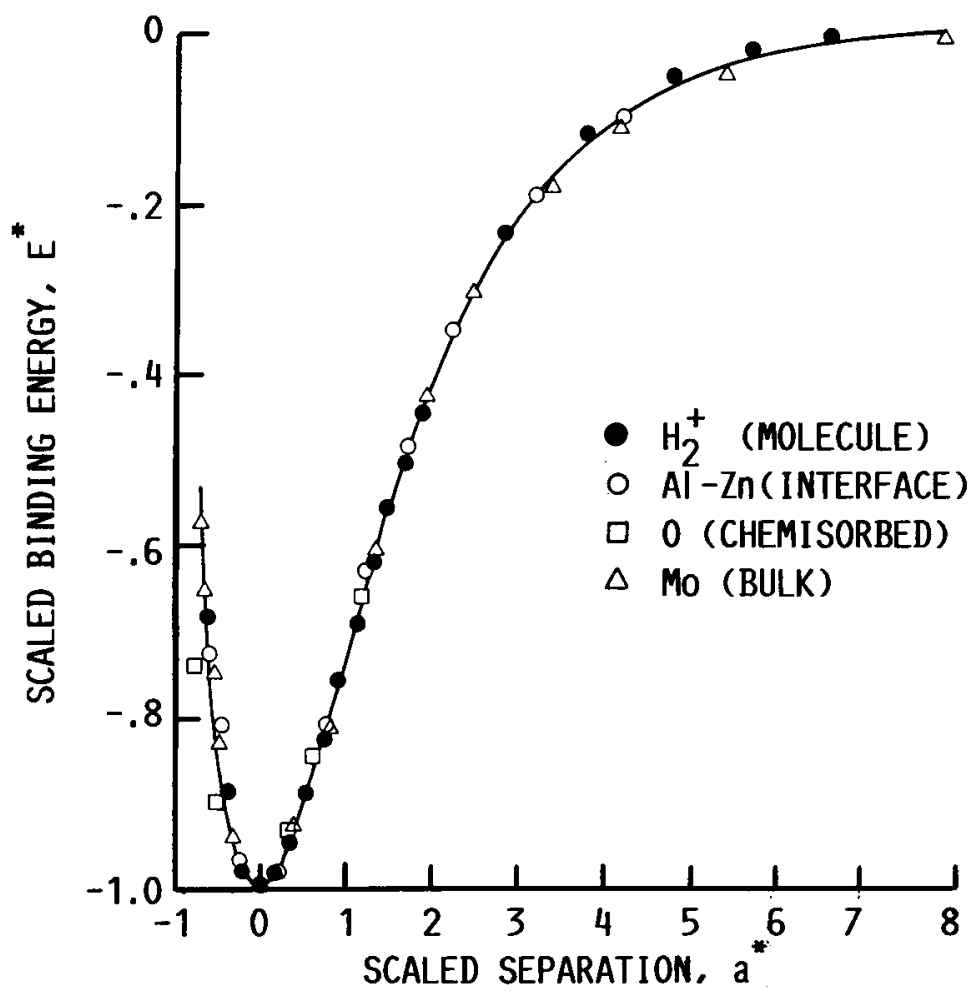

FIGURE 10. - BINDING ENERGY AS A FUNCTION OF INTERATOMIC SEPARATION FOR FOUR SYSTEMS AS NOTED. 


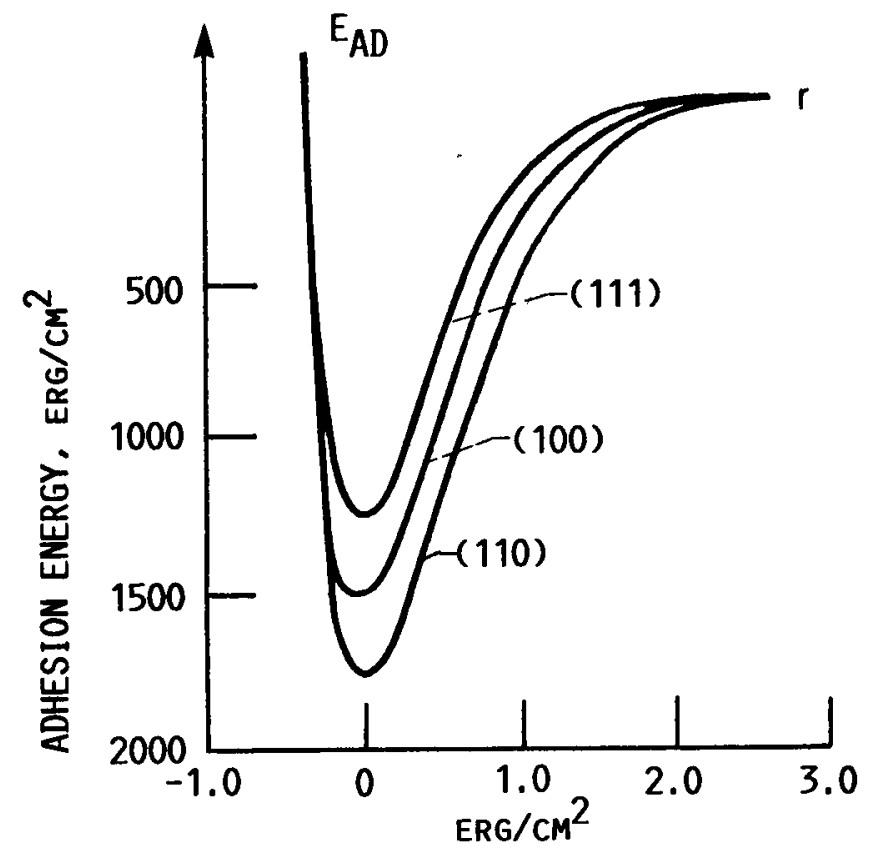

FIGURE 11. - SURFACE ENERGY AS A FUNCTION OF SEPARATION FOR 3 PLANES OF NICKEL. 


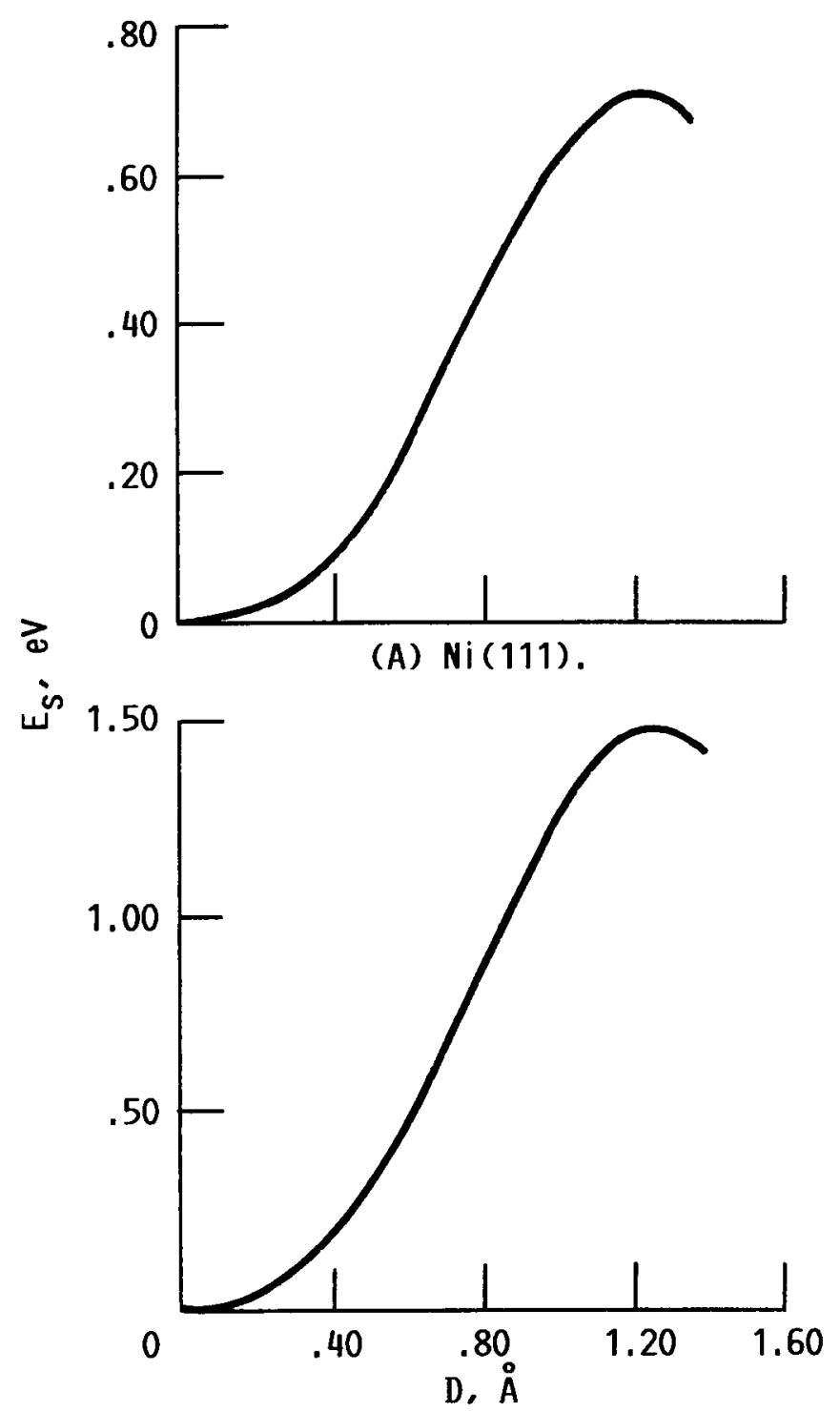

(B) $\mathrm{Ni}(100)$.

FIGURE 12. - BARRIER TO SLIP ON TWO PLANES OF Ni IN THE MINIMUM ENERGY DIRECTION. 


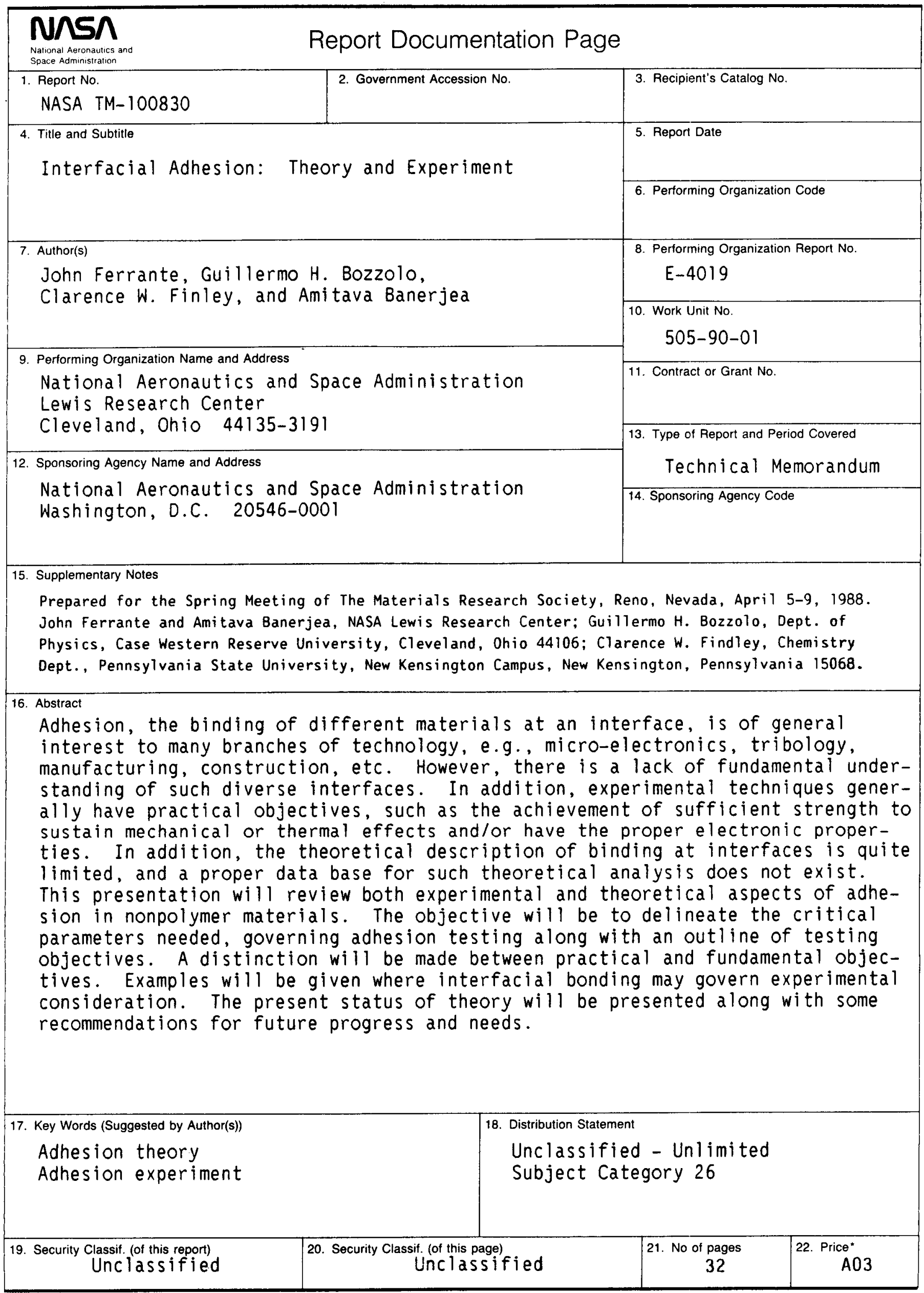

